\section{Serum Aldosterone Levels In Hemodialysis Patients: A Systematic Review}

Mariana Jancis Rigolo ${ }^{1}$ Marcelo Rodrigues Bacci², Neif Murad', Antonio Carlos Palandri Chagas ${ }^{1}$,

Beatriz da Costa Aguiar Alves ${ }^{3}$, Fernando Luiz Affonso Fonseca $^{3,4}$

1 Department of Cardiology, ABC Medical School, Av. Principe de Gales, 821, CEP 09060-650, Santo André, SP, Brazil.

2 Department of General Practice, $A B C$ Medical School, Av. Principe de Gales, 821, CEP 09060-650, Santo André, SP, Brazil.

3 Clinical Laboratory, ABC Medical School, Av. Principe de Gales, 821, CEP 09060-650, Santo André, SP, Brazil.

4 Biological Sciences Department, Federal University of São Paulo, R. Prof. Arthur Riedel, 275, CEP 09972-270 Diadema, São Paulo, Brazil.

\section{Contact information:}

Marcelo Rodrigues Bacci.

Tel: (055) 11981937005

Address: Av. Principe de Gales, 821, Vila Principe de Gales,

Santo Andre -São Paulo-Brazil0

झmrbacci@yahoo.com

Conclusion: It was observed that aldosterone blockade in hemodialysis patients represents an important and safe therapeutic strategy owing to the consequent proteinuria and blood pressure reduction. These factors help reduce cardiovascular risk. Moreover, this strategy contributes to decrease renal injury, suggesting a beneficial effect on the prevention of chronic kidney disease.

\title{
Keywords
}

Aldosterone, Hemodialysis, Spironolactone, Renin-Angiotensin-Aldosterone System 


\section{Background}

Dialysis is a treatment widely used by chronic kidney disease patients in Brazil. The data provided by the Brazilian Nephrology Society [1] indicate that between the years 2003 and 2013 the number of patients under dialysis gradually increased, going from 42,695 cases in 2000 to 100,397 in 2013, with more than half of these cases concentrated in the south and southeast of the country. In July of 2011, it can also be observed that $90.6 \%$ of these patients were undergoing hemodialysis and only $9.4 \%$ peritoneal dialysis [2].

It is also known that a great part of the patients who undergo dialysis not only suffer from chronic kidney disease but also from cardiovascular diseases. In an attempt to reduce the incidence of this kind of pathology, many of these patients start an antihypertensive treatment that includes medications like angiotensin receptor blockers and angiotensinconverting enzyme inhibitors.

Aldosterone, a type of mineralocorticoid which especially targets the kidneys, is secreted by the adrenal gland. It is produced from cholesterol when LDL molecules bind to coated pits on the adrenocortical cell membranes and are internalized by endocytosis, forming vesicles that, once in contact with lysosomes, form cholesterol vesicles.

Aldosterone function consists in the regulation of the electrolyte balance as it acts in the increase of natremia; in other words, it acts not only on renal tubular cells, thus increasing the active sodium transport to the extracellular space, but also on the passive sodium reabsorption of the urinary filtrate. Simultaneously, it increases potassium secretion through renal tubular epithelial cells, especially in the principal cells of the renal tubules. In sum, aldosterone makes sodium be preserved in the extraceIlular liquid as potassium is excreted in the urine [3].

Whenever aldosterone depletion occurs, potassium ion concentration in the extracellular liquid may increase, and when this increase reaches 60 to $100 \%$, a high cardiac toxicity, with a decrease in contraction strength and arrhythmias, can be observed.

Aldosterone plays an important pathophysiological role given the fact it is related to the stimulation of cytokines, inflammatory cell recruitment and the participation in the production of growth factors. In addition, it not only modulates plasminogen activator inhibitor but also is the key to the regulation of ion homeostasis. The mineralocorticoid receptors are present in epithelial and in many non-epithelial tissues, including the brain and the heart. Due to the paracrine/autocrine effects it exerts, aldosterone can induce endothelial dysfunction, reduce vascular compliance and cause vascular and myocardial fibrosis.

Potassium ion concentration and the renin-angiotensin system are the most important factors in aldosterone secretion regulation. This hormone, in turn, acts on the kidneys contributing to the excretion of potassium ion excess and increasing blood volume and, as a result, blood pressure [4].

\section{Chronic Kidney Disease}

Chronic kidney disease (CKD) refers to a persistent renal dysfunction in which the kidneys are permanently prevented from playing their habitual roles. In such cases, a slow, progressive and irreversible depletion of a great number of functional nephrons occurs [5].

$C K D$, defined as the persistent reduction of creatinine clearance to levels lower than $60 \mathrm{ml} /$ min/1.73m2 during the period of 3 months and/or the alteration in the renal parenchymal architecture, is a known high risk factor for the development of cardiovascular diseases [6].

The main etiologies for CKD and terminal kidney diseases (TKD) are diabetes mellitus and hypertension. These factors, along with other elements of the metabolic syndrome, like obesity, contribute to the development and progression of renal injuries [6]. 
Among the patients with CKD, a relation between a progressive increase in cardiovascular diseases as renal function decreases can be observed regardless of any pre-existing cardiovascular disease. A population study performed by the National kidney Foundation [7] showed that the lower the glomerular filtration rate is, the higher the chances are of occurring cardiovascular events, a fact that confirms the relation mentioned above.

\section{Aldosterone in Dialysis Patients}

A treatment strategy that has been used with dialysis patients nowadays includes the inhibition of aldosterone action or production. It impairs higher reabsorption of sodium and, as a consequence, contributes to a decrease in the blood volume with a resultant steadiness of blood pressure and the non- interference with the already compromised renal function. Moreover, since CKD is usually associated with a cardiopathy, the technique protects the often-injured cardiac muscle and helps prevent future injuries to it.

Recent studies show that aldosterone exerts many potentially important effects on cardiovascular and renal diseases once it is also related to oxidative stress levels through the induction of $\mathrm{NADPH}$-oxidase and the promotion of vascular inflammation. In addition, not only does it decrease the bioavailability of nitric oxide by altering the endothelial function, but it can also cause cardiac hypertrophy and fibrosis [8].

Today it is known that high levels of aldosterone in dialysis patients increase the risk of sudden cardiovascular death; therefore, the control of these levels in such patients is of the utmost importance.

Aldosterone antagonists -spironolactone and eplerenone- act on the distal sodium-potassium exchange, which causes an important anti-hypertensive effect, play a vital role in prolonging survival in patients under dialysis and prevent hypokalemia when associated with other thiazide diuretics. These drugs compete with aldosterone for their intracellu- lar receptors thus inhibiting sodium retention and potassium secretion at a distal level [9].

The aim of the current study was to perform a systematic review on what has been published regarding aldosterone levels in hemodialysis patients.

\section{Methods}

A systematic review was performed in order to identify possible eligible studies from the databases Lilacs and Medline with the descriptors (MeSH) "aldosterone" AND "hemodialysis". Those articles published in the English language until 2014 that used human subjects in the trials and had available abstracts were included.

Articles that related aldosterone to hemodialysis in their titles or abstracts were included.

The review was carried out by two independent researchers and evaluated by a third party investigator when the work was done.

In both databases, articles with animal trials or case reports whose titles or abstracts did not contain the selected descriptors or relevant information that complied with the aim of the study were excluded.

\section{Results}

Table 1 shows the relation between the selected articles and their objectives. Figure 1 shows the articles inclusion and exclusion flowchart according to the criteria previously established. 
Table 1. Articles selected and objectives.

\begin{tabular}{|c|c|c|c|}
$\begin{array}{c}\text { Author } \\
\text { (Year) }\end{array}$ & Year & \multicolumn{1}{|c|}{ Study Desing } & \multicolumn{1}{c|}{ Objective } \\
\hline $\begin{array}{c}\text { Dreschler et } \\
\text { al [10] }\end{array}$ & 2013 & Cohort & $\begin{array}{l}\text { To analyze the relationship between cortisol and aldosterone } \\
\text { on the risk of sudden death from cardiac events in patients } \\
\text { undergoing hemodialysis. }\end{array}$ \\
$\begin{aligned} \text { Matsumoto } \\
\text { et al [11] }\end{aligned}$ & 2014 & Clinical Trial & $\begin{array}{l}\text { Analyze if spironolactone reduces the high incidence of } \\
\text { mortality and morbidity on cardiovascular and cerebrovascular } \\
\text { events in hemodialysis patients. }\end{array}$ \\
\hline $\begin{array}{c}\text { Flevari et al } \\
\text { [12] }\end{array}$ & 2013 & Clinical Trial & $\begin{array}{l}\text { To investigate the effect of spironolactone in hemodialysis } \\
\text { patients without heart failure. }\end{array}$ \\
\hline $\begin{array}{c}\text { Morishita et } \\
\text { al [13] }\end{array}$ & 2011 & Clinical Trial & $\begin{array}{l}\text { To evaluate the efficacy of a direct renin inhibitor, aliskiren, on } \\
\text { blood pressure and cardiovascular biomarkers for cardiovascular } \\
\text { diseases. }\end{array}$
\end{tabular}

Morishita et $2011 \quad$ Review

al [14]

\begin{tabular}{c|c|c}
$\begin{array}{c}\text { Nakano et al } \\
{[15]}\end{array}$ & 2010 & Clinical Trial \\
$\begin{array}{c}\text { Chua et al } \\
{[16]}\end{array}$ & 2012 & Review \\
\hline $\begin{array}{c}\text { Baker et al } \\
{[17]}\end{array}$ & 2012 & Review \\
$\begin{array}{c}\text { Matsumoto } \\
\text { et al [18] } \\
\text { Hung et al } \\
\text { [19] }\end{array}$ & 2009 & Clinical Trial \\
\hline
\end{tabular}

Bomback et 2009 Cross Sectional
Discuss the effects of blockers of the renin-angiotensinaldosterone system in hemodialysis patients on the control of hypertension and prevention of cardiovascular diseases.

Comparatively analyze the use of efenodipina and amlodipine in patients on hemodialysis in relation to its effect on the reninangiotensin-aldosterone system.

Systematically review the evidence of the use of spironolactone in hemodialysis patients and the incidence of hyperkalemia.

Evaluate the support given by the literature on the use of mineralocorticoid antagonists in hemodialysis patients.

Evaluate the safe use of low doses of spironolactone in oliguric patients on hemodialysis.

Analyze the role of volume overload in the relationship between aldosterone and mortality in hemodialysis patients.

To show that the loss of renal function entails a change in the ratio of volume expansion with aldosterone levels.

Figure 1: Revision of literature flowchart.

\begin{abstract}
"Aldosterone" ADN "Hemodialysis" Medline: 221 articles
\end{abstract}

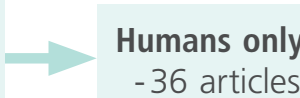

\section{English - 34 articles}

Selected: 9 articles. - 3 clinicla trials - 3 preospective cohort -3 reviews

Selected: 7 articles.

"Aldosterone" ADN "Hemodialysis" Lilacs: 457 articles

Humans only - 48 articles
English

-42 articles
With abstract - 38 articles
- 1 cross sectional

- 1 prospective cohort

- 5 clinicla trials 


\section{Discussion}

\section{Cardiovascular Mortality Reduction}

In a cohort study carried out by Dreschsler et al. [10], 1255 patients were followed up for 4 years. The aim was to evaluate if aldosterone and cortisol concentrations may affect cardiovascular mortality and morbidity rates in patients with type 2 diabetes undergoing hemodialysis. After this period the author observed that high levels of aldosterone were directly related to cardiovascular sudden death. The risk of sudden death was 69\% higher in the group of patients with aldosterone levels higher than 200pg/ mL when compared with the group of patients with levels lower than $15 \mathrm{pg} / \mathrm{mL}$. Therefore, the study demonstrated that the high levels of aldosterone in these patients were directly related to the increase in the risk of cardiovascular sudden death. According to the authors, the use of aldosterone antagonist medications could be a strategy to help reduce this death rate.

According to Matsumoto et al. [11], spironolactone, an aldosterone receptor inhibitor, slows atherosclerosis progression with a resultant cerebro- and cardiovascular prevention, even when in small doses, in hemodialysis patients. In his randomized stu$d y$, the author divided the patients into 2 groups: those who were medicated and those who were not. During the three-year follow-up the group that did not receive the medication had a higher rate of cardio- and cerebrovascular events (control group, with $12.5 \%$ ) than the medicated group (with $5.7 \%$ ). Therefore, the conclusion is that with the use of spironolactone the risk of cardio- and cerebrovascular deaths can be reduced, especially among hemodialysis patients.

Flevari et al. [12] states that the use of spironolactone in hemodialysis patients with cardiac insufficiency has proved to be very effective when it comes to decreasing the risk of cardiovascular diseases. However, data on the use of this medication in patients without cardiac insufficiency are still very scarce. In his study, fourteen hemodialysis patients without cardiac insufficiency received a placebo for four months and spironolactone for another four (25 mg three times a week after the dialysis session). At the end of the study, spironolactone induced beneficial effects not only in the duration and extension of reactive hyperemia but also in heart rate variability and blood pressure control. Thus, authors concluded that the use of this medication in these patients may be beneficial in cardiovascular outcomes. In other words, it may decrease cardiovascular mortality.

\section{Renin-Angiotensin-Aldosterone System (RAAS) Blockade}

In a clinical trial conducted by Morishita et al. [13], a total of 30 hypertensive hemodialysis patients received aliskiren, a direct renin inhibitor, for 8 weeks. After the follow-up period, the medication reduced systolic and diastolic pressure in patients and inhibited markers of cardiovascular diseases, like natriuretic peptide and C-reactive protein. The result suggests that aliskiren was effective in the blood pressure control and that it must have a protective cardiovascular effect on hypertensive hemodialysis patients.

The RAAS inhibition in hypertensive hemodialysis patients can prevent cardiovascular diseases [14]. Previous studies show that the use of RAAS inhibitors may be effective in the blood pressure control to prevent cardiovascular disease in hemodialysis patients. Therefore, this review reinforces the idea that these medications exert beneficial effects on this group of patients.

A randomized study carried out by Nakano et al. [15] compared the effects of efonidipine and amlodipine, two calcium channel blockers, on the RAAS in hemodialysis patients. Twenty hypertensive hemodialysis patients randomly received 20-60 $\mathrm{mg}$ of efonidipine twice a day and 2.5-7.5 mg of amlodipine once a day over a period of 12 weeks. Besides the measurement of blood pressure before 
each dialysis session, routine hematological tests were performed and circulating RAAS system components were evaluated. At the end of the follow-up period, it was observed that systolic and diastolic pressure was significantly reduced by efonidipine. However, diastolic pressure did not reach statistical significance while amlodipine was being administered despite the fact plasma renin activity and angiotensin II levels did not significantly vary during both periods. Results suggest that efonidipine not only blocks calcium channels but also suppresses aldosterone secretion by the adrenal glands. Thus, besides its anti-hypertensive effect, efonidipine also provides cardiovascular protection against the harmful effects of aldosterone through a different mechanism than RAAS inhibitors.

\section{Aldosterone Antagonism and Hyperkalemia}

In order to analyze the medication safety in hemodialysis patients, Chua et al. [16] conducted a review that evaluated the incidence of hyperkalemia in those patients that made use of spironolactone. The conclusion was that the use of spironolactone has been proved to be safe in patients with chronic kidney disease undergoing short-term therapy under a strict control of electrolyte concentrations. Despite the results, the author believes that the use of the medication in the general population with cardiac insufficiency undergoing hemodialysis would be hasty and it should not be done indiscriminately at the present moment.

In a review published by Baker \& White [17], ten articles were evaluated: nine on the use of spironolactone and one on the use of eplerenone analyzing the impact on potassium levels in this population. The use of spironolactone and eplerenone, when in small doses, showed a slight increase in potassium concentration. The current literature shows that the use of mineralocorticoid receptor blockers can be safely used in hemodialysis patients, although further studies that include larger populations are required for this recommendation.

According to a clinical trial performed by Matsumoto et al. [18], the use of small doses of spironolactone in oliguric patients on hemodialysis in the long run is clinically safe and it can reduce mortality rate among these patients. Nonetheless, the study also revealed that among these patients under study, eleven of them had to interrupt the medication owing to the fact they presented with hyperkalemia. The rest of the studied population, a total of 50 patients, showed higher potassium levels when compared with the levels in the beginning of the trial. Therefore, the use of this medication should be approached with caution.

\section{Hypervolemia}

In a cohort study carried out by Hung et al. [19], the outcome of 328 hemodialysis patients was evaluated. Among these patients, a total of $36 \%$ showed evidence of fluid volume excess; namely, the relation between extracellular water and total volume was higher than $48 \%$ in these patients. Moreover, the group with high aldosterone levels had lower rates of mortality and cardiovascular events. Therefore, the study showed that in patients with hypervolemia, aldosterone no longer poses as a risk factor, but as a protection factor.

In another study by Bomback et al. [20], hemodialysis patients showed an irregular relation between blood volume and aldosterone concentration. In the study, the relation comparison was between hemodialysis patients and non-hemodialysis volunteers. The result was that the rates of aldosterone and extracellular volume were higher in hemodialysis than in the evaluated volunteers. With these data, the conclusion is that both volume reduction and the use of mineralocorticoid blockers may be effective treatment approaches.

\section{Arterial Pressure Control}

In a study conducted by Shavit et al. [21], the hypothesis that aldosterone may cause hyperten- 
sion in a manner that does not involve renal sodium retention was tested. The author administered eplerenone twice a day over a period of 4 weeks. This aldosterone antagonist administration lowered the systolic pressure, but showed no effect on the diastolic pressure and aldosterone concentration. In sum, the medication reduced the systolic pressure without exerting effects on aldosterone plasma concentrations or on plasma renin activity. Potassium concentration slightly increased, a fact that leads us to the conclusion that the medication should be used with caution.

\section{Carotid Intima-Media Thickness Regression}

Among the effects presented by spironolactone, one is its capacity to inhibit the progression of the carotid intima-media thickness. In order to establish a dosage pattern regarding its safety and effectiveness, Vukusich et al. [22] randomly administered the medication and placebo to 50 hemodialysis patients. Administration was carried out three weeks later, after each dialysis session, over a period of two years. Periodic potassium concentration measurements were performed, and at the end of the second year, subjects underwent a carotid ultrasound. A progression in carotid thickness values in the placebo group was seen whereas in the spironolactone group a regression could be observed. Thus, the medication showed a beneficial effect on the regression of intima-media thickness.

\section{Cardiac Performance}

Another spironolactone effect on hemodialysis patients is the probable improvement in the cardiac function. In a double-blind trial performed by Taheri et al. [23], a total of 16 hemodialysis patients were divide into 2 groups, and each received either placebo or spironolactone over a period of 6 months. Patients from the spironolactone group showed an increase in the ejection fraction when compared with the patients from the placebo group. Rates of hyperkalemia did not show any significant increase in either group. Therefore, as the use of spironolactone implied an increase in the ejection fraction, it is observed that the medication can improve the cardiac performance.

In conclusion, there is a very close relation between aldosterone values and chronic kidney disease patients undergoing hemodialysis. The current systematic review showed important interaction between the renin-angiotensin-aldosterone system, hypervolemia, cardiovascular mortality and alternative medications for aldosterone inhibition and a proper pressure control.

\section{Conclusion}

In conclusion, high levels of aldosterone in hemodialysis patients were directly related to the increase in the risk of cardiovascular sudden death and hypervolemia, and the use of aldosterone antagonist medications such as spironolactone could be a strategy to help reduce this death rate. Moreover, spironolactone is also associated to the progression of the carotid intima-media thickness inhibition and improvement in the cardiac function. However, the use of this medication should be approached with caution since it is related to some hyperkalemia events. Cardiovascular protection against the harmful effects of aldosterone is also provided by efonidipine, that besides blocking calcium channels also suppresses aldosterone secretion by the adrenal glands.

\section{References}

1. Dialysis Census of the Brazilian Society of Nephrology 2013. Available at: www.sbn.org.br [accessed 01/dec/2014].

2. Sesso RC, Lopes AA, Thomé FS, Lugon JR, Watanabe Y, Santos DR. Report of the Brazilian Chronic Dialysis Census. J Bras Nefrol 2012; 34: 272-277.

3. Guyton \& Hall. Adrenocortical Hormones. In: Treaty of Medical Physiology, 12th ed. Rio de Janeiro. Elsevier, 2011, p. 972-5.

4. Formenti S, Schoorlemmer GHM, Moreira TS, Colombari E. Central nervous system and aldosterone: Role on cardiovascular control and hydro-electrolytic homeostasis. Brazilian Archives of Health Sciences 2008; 33: 54-63. 
5. Bastos MG, Kirsztajn GM. Chronic kidney disease: importance of early diagnosis, immediate referral and structured interdisciplinary approach to improve outcomes in patients not yet on dialysis. J Bras Nefrol 2011; 33: 93-108.

6. Maric-Bilkan C. Obesity and diabetic kidney disease. Med Clin North Am. 2013; 97: 59-74.

7. Go AS, Chertow GM, Fan D, McCulloch CE, Hsu CY. Chronic kidney disease and the risk of death, cardiovascular events, and hospitalization. N Engl J Med 2004; 351: 1296-1301.

8. Chaves PM. Myocardial effects of angiotensin II and its implications in the pathophysiology of heart failure. Porto University, 2004

9. Rang HP, Dale MM, Ritter JM,Flower RJ, Henderson G. The Kidney. In: Rang \& Dale. Pharmacology. 7th ed. Rio de Janeiro. Elsevier, 2012, p 355

10. Drechsler C, Ritz E, Tomaschitz A, Pilz S, Schönfeld S, Blouin K et al. Aldosterone and cortisol affect the risk of sudden cardiac death in haemodialysis patients. Eur Heart J 2013; 34: 578-87.

11. Matsumoto $Y$, Mori $Y$, Kageyama S, Arihara K, Sugiyama $\mathrm{T}$, Ohmura $\mathrm{H}$ et al. Spironolactone reduces cardiovascular and cerebrovascular morbidity and mortality in hemodialysis patients. J A Coll Cardiol 2014; 63: 528-36.

12. Flevari $P$, Kalogeropoulou S, Drakou A, Leftheriotis D, Panou $F$, Lekakis J et al. Spironolactone improves Endothelial and Cardiac Autonomic Function in Non Heart Failure Hemodialysis Patientes. J Hypertens 2013; 31: 1239-44.

13. Morishita $Y$, Hanawa S, Chinda J, limura O, Tsunematsu $S$, Kusano E. Effects of aliskiren on blood pressure and the predictive biomarkers on cardiovascular disease in hemodialysisdependent chronic disease patients with hypertension. Hypertens Res 2011; 34: 308-13.

14. Morishita Y, Kusano E. The blockade of renin-angiotensinaldosterone system in hemodialysis patients to control hypertension and prevent cardiovascular disease: optimal pharmacotherapy. Cardiovasc Hematol Agents Med Chem 2011; 9: 241-6.

15. Nakano N, Ishimitsu $T$, Takahashi $T$, Inada H, Okamura A, Ohba $S$ et al. Effects of Efonidipine, an L- and T-type Calcium Channel Bocker, on the Renin-angiotensin-aldosterone System in Chronic Hemodialysis Patients. Int Heart J 2010; 51: 188-92.

16. Chua D, Lo A, Lo C. Spironolactone use in heart failure patients with end-stage renal disease on hemodialysis: is it safe? Clin Cardiol 2010; 33: 604-8

17. Baker WL, White WB. Safety of Mineralocorticoid Receptor Antagonists in Patients Receiving Hemodialysis. Ann Parmacother 2012; 46: 889-94

18. Matsumoto Y, Kageyama S, Yakushigawa T, Arihara K, Sugiyama $\mathrm{T}$, Mori $\mathrm{Y}$ et al. Long-term low-dose spironolactone therapy is safe in oligoanuric hemodialysis patients. Cardiology 2009; 114: $32-8$.
19. Hung SC, Lin YP, Huang HL, Pu HF, Tarng DC. Aldosterone and mortality in hemodialysis patientes: role of volume overload. PLoS One. 2013; 8: e57511.

20. Bomback AS, Kshirsagar AV, Ferris ME, Klemmer PJ. Disordered aldosterone-volume relationship in end-stage kidney disease. J Renin Angiotensin Aldosterone Syst 2009; 10: 230-6.

21. Shavit L, Neykin D, Lifschitz M, Slotki I. Effect of eplerenone on blood pressure and the renin-angiotensin-aldosterone system in oligo-anuric chronic hemodialysis patients- a pilot study. Clin. Nephrol 2011; 76: 388-95

22. Vukusich A, Kunstmann S, Varela C, Gainza D, Bravo S, Sepulveda $D$ et al. A randomized, double-blind, placebo-controlled trial of spironolactone on carotid intima-media thickness in nondiabetic hemodialysis patients. Clin J Am Soc Nephrol 2010; 5: 1380-7.

23. Taheri S, Mortazavi M, Shahidi S, Pourmoghadas A, Garakyaraghi M, Seirafian S, Eshaghian A et al. Spironolactone in chronic hemodialysis patients improves cardiac function. Saudi J Kidney Dis Transpl 2009; 20: 392-7.

\section{Comment on this article:}

\section{(f) [3] in $8+\mathbf{S}$ P}

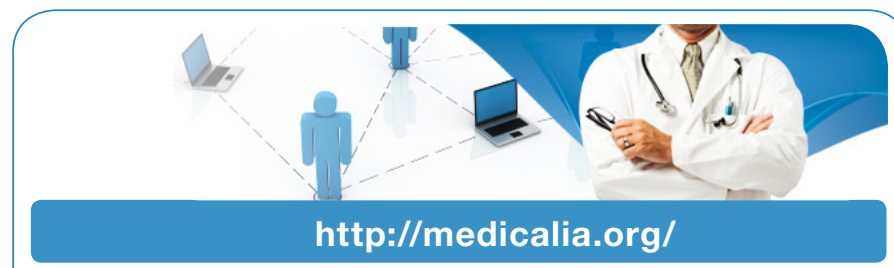

Where Doctors exchange clinical experiences, review their cases and share clinical knowledge. You can also access lots of medical publications for free. Join Now!

\section{Publish with iMedPub}

http://www.imed.pub

International Archives of Medicine is an open access journal publishing articles encompassing all aspects of medical science and clinical practice. IAM is considered a megajournal with independent sections on all areas of medicine. IAM is a really international journal with authors and board members from all around the world. The journal is widely indexed and classified Q1 in category Medicine. 